\title{
Analysis on the Cultivation of Students' Professional Spirit in Higher Vocational Colleges
}

\author{
Li Xuanyi ${ }^{1}$ \\ ${ }^{1}$ Jilin Communications Polytechnic, Changchun, Jilin, 130000
}

Keywords: vocational and technical education; ideological and political education; professionalism

\begin{abstract}
In recent years, graduates have been increasing year by year, and the employment competition is getting much fiercer. The employers pay more attention to the students' professionalism according to the professional level, which requires higher vocational colleges in nurturing students, to not only focus on theoretical teaching, but also pay attention to the cultivation of student professionalism. This paper puts forward the manifestation of the lack of professionalism of students in higher vocational colleges, finds out the causes of these deficiencies, and puts forward corresponding countermeasures and methods, giving full play to the exemplary role of professionalism training, from strengthening the ideological and political education from the perspective of improving the professionalism in higher vocational Colleges.
\end{abstract}

\section{Lack of Professionalism Performance}

In recent years, as a counselor and a political education teacher in higher vocational colleges and universities, through the communication with students, the survey shows that the lack of professionalism among students in higher vocational colleges and universities has the following kinds of performance:

\subsection{Focus on professional courses and ignore basic courses}

Students entering higher vocational colleges think that learning the knowledge of specialized courses will help them find jobs in the future. Therefore, when setting up a specialized course, some students are very hard to learn, professional achievement is very good, but the basic course performance is poor. For such courses as "Ideological and Moral Cultivation and Legal Basis" and "Mental Health of College Students" turn a blind eye, they find it useless and neglect their own moral education and mental health problems [1].

\subsection{Lack of firm will}

There are many students confused when facing job, do not know what they can do? Some lack confidence in themselves, others are too self-confident about themselves and can not have a clear definition of themselves. Some work to do for a period of time decided to give up, think this post can not see the future, so do it in the future is no development. Or when faced with some problems and conflicts, do not want to know how to solve, but choose to avoid and give up. So always the opposite, there is no firm will, there is no clear goal.

\subsection{Lack of integrity}

Honesty education is a very important part. During college, undergraduates' world outlook, outlook on life and values are not yet fully mature, and they are easily influenced by some unhealthy practices in society and schools, seriously affecting their moral choices. Cheating, deceiving teachers, parents, borrowing overdue and so on are not uncommon. In the job search job, the lack of integrity and mission, a long way ahead, pretentious, and even the phenomenon of resume fraud occurs, after the job can not perform their duties in full employment contract, arbitrary breach of contract, lack of integrity [2]. 


\subsection{Lack of responsibility}

Sleep in class, late, absent Participated in group activities, withdrawing for no reason while feeling bored, with no sense of collectivism. For the final exam holding long live the attitude, in order to successfully get the diploma chaos college life, there is no ideal, with no ambition, light social interests, only the personal interests, the phenomenon of egocentric serious.

\section{The Reasons for the Lack of Professionalism for Students in Higher Vocational Colleges}

\subsection{Schools lack awareness of professionalism}

Nowadays in the education of higher vocational and technical colleges and universities, the emphasis on vocational ability education is more obvious, while neglecting the cultivation of students' professionalism. For vocational ability, in the teaching process, teachers pay more attention to the instilling and training of theoretical knowledge in teaching plan and teaching task, while ignoring the cultivation of students' professionalism. The contempt that the school cultivates to the professional spirit has direct influence on the teacher's teaching idea in the teaching process. In the process of teaching, only the professional knowledge is imparted to the students through the theoretical teaching, with no emphasis on the cultivation of the humane spirit [2].

\subsection{The traditional teaching model affects the cultivation of students' professionalism}

Nowadays higher vocational colleges and universities lack the cutting-edge concepts of running schools and the hardware facilities for running schools are not yet perfect. Although some facilities are complete, the utilization rate is not high. Lead to no new schooling results, can not afford to mobilize the enthusiasm of students. Such teaching mode seldom gives students the chance to get in touch with social practice and improve their abilities so that students will only stay in the stage of theoretical study for the major they are studying while still confused with the actual operation. Students come to college, first of all, the university is full of curiosity and longing, but for boring teaching methods, and gradually makes students lose interest in learning, thus reducing the quality of teaching. However, the teachers failed to communicate with the students in time and the teaching methods have not been innovated, thus resulting in the failure to integrate vocational education into the theoretical teaching. In addition, the current evaluation of professionalism education is also relatively simple evaluation, academic performance or occupy a large part of the proportion of this spirit is virtually identical with the study of learning, can not truly reflect the students have a good professionalism, at the same time, the training effect of professionalism has also been greatly affected. Objectively speaking, this evaluation method is not scientific, which has a direct impact on the ideal effect to be achieved in professional spirit cultivation [3].

\subsection{The school's educational philosophy and management model failed to align with the new education}

Most of the higher vocational colleges and universities are the transformation of the past secondary school, from the level of teachers to the overall level of the students have a large part of the improvement, but in the teaching philosophy and management model failed to link with the university. Teachers are still paying more attention to the teaching of theory, constantly instilling theoretical knowledge into students and failing to give students more autonomy in the management of schools. Such students are dependent on the school, but also that they are not grown children, do not take the initiative to think and deal with. And there are few schools in the field of professionalism. At present, only a small part is mentioned in the course of "Ideological and Moral Cultivation and Law Basis". Counselors in schools also have not been professionally trained, and there may be some lack of education for students. In terms of campus culture, there is also a lack of training for professionalism. Some students participate in associations easily. 


\section{Vocational College Students Need Develop Vocational Skills and Methods}

\subsection{To create a good environment to cultivate the professionalism}

While instilling professionalism in theory, it is easier for students to accept it through edutainment. Organizations now have more and more activities. They can organize more activities under the theme of "Dedication and Responsibility" so that students can enhance their self-confidence and sense of responsibility through activities. We can also propagandize professionalism education through various media such as campus radio, banners and WeChat platforms to deepen the role of ideological and political education so that this spirit can be inadvertently imparted to the students' eyes and hearts. The education in schools can not be divorced from the society and can be taken as a way to bring business to school. Such as the outstanding employees and corporate culture brought to the campus to promote the integration of school education and corporate culture, to narrow the distance between the campus and businesses so that students can learn more about the community and improve their understanding of professionalism [3].

\subsection{To continuously change the concept of personnel training}

Higher vocational colleges in teaching philosophy should keep pace with the times, constantly updated. In the teaching content of higher vocational colleges, the professional theory course is a very important part, but it is not a single part, but also attach importance to the education of students' moral education. Teachers need to be connected with the needs of society in the teaching of professional theoretical courses, and to integrate vocational education into them, and to strengthen the cultivation of professionalism. It is necessary to continuously emancipate the mind, take the employment goal as the orientation, and face the market of society and society as a whole. Students should be able to adapt more quickly to the needs of the society and the market after moving to work. Teachers should give examples of their teaching according to different majors and students of different grades. The actual work may encounter situations through the scene simulation shows the way to inform students of the future work environment, job responsibilities, etc., so that students more vividly understand the future to be engaged in the occupation and working environment. In the process of teaching, teachers should constantly update the teaching philosophy, innovate teaching methods, improve their own knowledge, so as to better improve the teaching mode of professionalism training for higher vocational college students to establish the correct career ideal Lay a good foundation [4].

\subsection{To improve the professionalism of teachers}

To improve teachers' professionalism and to enhance the construction of study style in campus are the preconditions to cultivate professionalism. Teachers are the main body of the implementation of school education. Teachers' values, outlook on life, moral cultivation, professionalism and teachers' daily deportment have the most direct and effective influence on students. Schools must improve teachers 'ethics, improve teachers' responsibility and reserve a contingent of people teachers with responsibility and dedication. In order to rigorously teaching attitude to educate students, with affection and love to care and infection of students, with a high moral and professional qualities to influence students. Second, the counselors should also strengthen the study of professionalism [5]. Counselors are the most direct ideological and political education guide for students in higher vocational colleges and universities. They are the most basic management teachers and the first-line teachers who have the most contact with students. Therefore, to strengthen the training of professional mentors of counselors and to raise their awareness of education can enhance the cultivation of professionalism education from students and daily life. In the end, we should attach importance to this position in the ideological and political education class. We should not only emphasize specialized courses. We should improve the proportion of ideological and political education classes, improve teaching hardware and equipment, give students more interest in this course through vivid multimedia presentations, and more willing to 
take the initiative to learn. In the process of teaching, according to the characteristics of different professions, we should conscientiously conclude the professional spirit that different professions should possess. Through vivid cases, let students summarize themselves and let their students have their own understanding and understanding of professionalism so as to enhance their enthusiasm Initiative.

\subsection{To establish an effective professional quality evaluation system}

Continuous encouragement and motivation can promote the interest of learning, effective evaluation system, can guarantee the effective implementation of professional spirit education, but also can inspire students to take the initiative to learn. To develop a reasonable system of evaluation standards for vocational students in higher vocational colleges, any evaluation must have a sound system basis, so that there is evidence to be based, more informative and persuasive. Evaluation system, in the content must refer to the characteristics of students and the needs of employers, improve the evaluation content, change the simple method of performance on the hero. In the evaluation of theoretical achievements at the same time, but also pay more attention to professionalism score. Will be active participation in school activities, whether a sense of responsibility, whether to adhere to honesty, dedication, whether there is a sense of team, as the basic requirements of evaluation. These are included in the comprehensive evaluation of students, when graduating can also refer to refer to the corresponding units, so that the employment rate can also guarantee the quality of employment. This professionalism quality assessment should be run through the entire learning stage of students, so as to be able to play a good role in education, supervision, and thus play a good educational effect [4].

\subsection{To strengthen the cooperation between school and enterprise}

At the time of cultivating vocational students in higher vocational college, it is necessary to strengthen the cooperation between school and enterprise. First of all, let students learn more theoretical knowledge in school, and cooperation with enterprises, for students to create a business to adapt to the pre-work environment, while strengthening the accumulation of practical experience and exercise. Higher vocational colleges should develop their own strengths according to their own teaching characteristics, train students, and continue to promote communication and cooperation with enterprises, and establish their own characteristics of professionalism training mode. Use of internship opportunities, so that students in strict accordance with the management of enterprises to strict demands on themselves to improve their awareness of the discipline, and strengthen the sense of responsibility to be able to adapt to the work environment and workplace patterns early enough to fully experience the corporate culture, the school should continue to follow up, and according to the situation in real time to adjust the teaching progress [5].

\section{Conclusion}

In short, with the constant development and progress of society, education has drawn much attention. We should pay attention to the cultivation of vocational education for students in higher vocational colleges. The training of students in higher vocational colleges during the school period is an important stage that directly affects their outlook on the world, outlook on life and values. The third concept also directly affects the performance of students in entering the society and on their jobs, Students of tertiary institutions to better serve the community, to contribute to the great Chinese dream of their own power.

\section{References}

[1] Ma Bin. Methods, Principles and Approaches to Cultivate Modern Professionalism in Higher Vocational College [J]. Vocational Education Journal, 2008, (10): 159

[2] Tong Shandong. Realistic Requirements and Inevitable Trends of Professional Talent Cultivation

[J]. Chinese Vocational and Technical Education, 2006, (2): 15-16 
[3] Luo Xiao. We need it - a special survey of professionalism [J]. Occupation. 2008, (19): 10

[4] Wang Yuling. Reflections on cultivating vocational students' professionalism [J]. Chinese Vocational and Technical Education, 2009, (31): 46

[5] Tang Yuhua. On vocational education and vocational college students under the vocational values of education [J] Shaoyang Teachers College, 2009,10 (2): 74-7 